GRASAS Y ACEITES 68 (4)

October-December 2017, e217

ISSN-L: 0017-3495

doi: http://dx.doi.org/10.3989/gya.0226171

\title{
Dispersed free phytosterols as structuring agents in lipid systems with reduced saturated fat
}

\author{
K.R.R. Godoi ${ }^{\mathrm{a},} \bowtie$, R.C. Basso ${ }^{\mathrm{b}}$, M.H.M. Buscato ${ }^{\mathrm{c}}$, L.P. Cardoso ${ }^{\mathrm{d}}$, T.G. Kieckbusch ${ }^{\mathrm{c}}$ and \\ A.P.B. Ribeiro ${ }^{a}$ \\ ${ }^{\mathrm{a}}$ Departament of Food Technology, School of Food Engineering, University of Campinas, Brazil. \\ ${ }^{b}$ Institute of Science and Technology, Federal University of Alfenas, Brazil. \\ ${ }^{\mathrm{c}} \mathrm{School}$ of Chemical Engineering, University of Campinas, Brazil. \\ ${ }^{\mathrm{d}}$ Department of Applied Physics, Institute of Physics, University of Campinas, Brazil. \\ ${ }^{\square}$ Corresponding author: kamila.ramponi@hotmail.com
}

Submitted: 28 February 2017; Accepted: 11 July 2017

SUMMARY: The negative effects of trans fatty acids and saturated fatty acids in food have been widely discussed and this has led to progressive changes in the legislation of many countries. The use of structuring agents or crystallization modifiers, as specific triacylglycerol and minor lipids have been indicated as the only viable alternative for obtaining low saturated fats with properties which are compatible with food application. In this context, phytosterols, natural products with hypocholesterolemic action, and hard fat-crystallization modulators, present a new option for structuring lipid matrices. This work characterized the effects of fully hydrogenated soybean oil and free phytosterols on the physical properties and crystallization behavior of palm oil and canola oil blends for the development of zero trans-fat bases with low levels of saturated fatty acids. The systems were evaluated for chemical composition, atherogenic index, solid fat profiles, microstructure, consistency, thermal behavior and polymorphism.

KEYWORDS: Canola oil; Crystallization; Fully hydrogenated soybean oil; Lipid structuring; Palm oil; Phytosterols

RESUMEN: Fitosteroles libres dispersos como agentes estructurantes en sistemas lipídicos reducidos en grasa saturada. Los efectos negativos de los ácidos grasos trans y los ácidos grasos saturados en los alimentos ha llevado a cambios progresivos en la legislación de muchos países. Se ha indicado que el uso de agentes estructurantes o modificadores de la cristalización, como triacilgliceroles específicos y componentes lipídicos menores, es la única alternativa viable para obtener grasas bajas saturadas que tienen propiedades compatibles con su aplicación en alimentos. En este contexto, los fitosteroles, productos naturales con acción hipocolesterolémica y moduladores de cristalización de la grasa saturada, se presentan como una reciente opción para estructurar matrices lipídicas. En este trabajo se realizó una caracterización del aceite de soja totalmente hidrogenado y fitoesteroles libres sobre las propiedades físicas y el comportamiento de cristalización de mezclas de aceite de palma/aceite de canola para el desarrollo de bases de grasas cero-trans con bajos niveles de ácidos grasos saturados. Seevaluó la composición química, el índice aterogénico, el perfil de grasa sólida, la microestructura, consistencia, y el comportamiento térmico y polimorfismo.

PALABRAS CLAVE: Aceite de canola; Aceite de palma; Aceite de soja totalmente hidrogenado; Cristalización; Estructuración lipídica; Fitosteroles

ORCID ID: Godoi KRR http://orcid.org/0000-0003-4115-0710, Basso RC http://orcid.org/0000-0002-1714-8322, Buscato MHM http://orcid.org/0000-0002-9053-6110, Cardoso LP http://orcid.org/0000-0003-3910-2293, Kieckbusch TG http://orcid.org/0000-0003-3074-8581, Ribeiro APB http://orcid.org/0000-0002-6532-1265

Citation/Cómo citar este artículo: Godoi KRR, Basso RC, Buscato MHM, Cardoso LP, Kieckbusch TG, Ribeiro APB. 2107. Dispersed free phytosterols as structuring agents in lipid systems with reduced saturated fat. Grasas Aceites $\mathbf{6 8}$ (4), e217. http://dx.doi.org/10.3989/gya.0226171

Copyright: (02017 CSIC. This is an open-access article distributed under the terms of the Creative Commons Attribution (CC-by) Spain 3.0 License. 


\section{INTRODUCTION}

The increasing incidence of cardiovascular disease in the last century led to an endless search for risk factors related to its development. Several studies have found that a relatively high intake of fat, especially trans and saturated fat, is a major contributor to the high incidence of coronary heart disease (Zevenbergen et al., 2009).Trans fatty acids are included among the dietary lipids that act as risk factors for coronary artery disease by modulating the synthesis of cholesterol and its fractions and acting on eicosanoids (Dhaka et al., 2011).Saturated fat is one of the main causes of the increase in plasma cholesterol, whose reduction in the diet is widely supported for reducing the risk of cardiovascular disease (Wassell et al., 2010).

Changing the composition of the lipid matrix in order to reduce the saturated fatty acid concentration and improve the lipid nutritional profile has become a strategic priority for food processing. For this purpose, the recent scientific literature indicates a potential alternative use of various components with structuring action and performance capacity in molecular or sub-micron levels in lipid matrices. These molecular agents may act on the process of structuring lipid systems as a whole, modulating properties such as thermal behavior, polymorphic stability and microstructure. Similarly, the effects of these modifiers on the macroscopic level, such as visual appearance, rheology and consistency has also been the subject of new studies (Rogers et al., 2014; Smith et al., 2011). In this context, different materials have been evaluated, such as trisaturated triacylglycerols, free fatty acids, partial glycerides, waxes, fatty alcohols, phospholipids, phytosterols and different classes of emulsifiers. However, a complete understanding of the effects of these modifiers in various lipid systems and their interactions, has not yet been completely established in the scientific literature (Ribeiro et al., 2015).

Mechanisms that rely on the incorporation of a crystallization modifier compound into a mixture require a concentration from $0.5 \%$ to $5 \%$ of the additives. On the other hand, if the primary action type occurs during the nucleation step in crystal forming, concentrations lower than $0.1 \%$ may be sufficient for modifying the process. A concentration which is lower than the last one may be sufficient for crystallization modifying when the mechanism is based on the blocking of the growth points of crystals. The position of the hydroxyl group and the number of double bonds in the carbon cyclic chain affect the characteristics of the crystal lattice or hinder its formation (Herrera; Marquez Rocha, 1996; Pernetti et al., 2007b; Smith et al., 2011).

The fatty acid composition of palm oil (PO) is characteristic and unique, with similar amounts of saturated and unsaturated fatty acids, mainly palmitic and oleic acids. In addition, PO has from 10 to $16 \%$ saturated fatty acid in the sn- 2 position of triacylglycerol molecules, resulting in specific crystallization properties (O'Brien, 2004).

Canola oil (CO) has, on average, $22 \%$ linoleic acid and a high content of oleic acid, about $60 \%$, with a low content in saturated fatty acids (about $6 \%$ ), resulting in a nutritionally favorable omega-3/ omega-6 ratio. Total tocopherol content is $770 \mathrm{mg} /$ $\mathrm{kg}$, higher than sunflower and corn oils, and the total sterol content is about $0.7 \%$, with $\beta$-sitosterol, campesterol and brasicasterol corresponding to $52.3 \%, 27.6 \%$ and $13.8 \%$, respectively (Gunstone et al., 2007; Przybylski et al., 2005).

Soybean oil is composed mainly of fatty acids with 18 carbon atoms. The average contents of stearic acid, oleic acid, linoleic acid and linolenic acid are $3.9 \%, 23.9 \%, 52.1 \%$ and $7.8 \%$, respectively (Dubois et al., 2007). In its fully hydrogenated form, soybean oil has $87.7 \%$ stearic acid, a saturated fatty acid that has no adverse metabolic effects (Gebauer et al., 2014). The addition of low contents of fully hydrogenated soybean oil (HSO) in some lipid matrices showed effective potential as a modifier of their crystallization and physical properties, as was reported in a study with cocoa butter (Ribeiro et al., 2013).

Phytosterols and phytostanols, the hydrogenated form of phytosterols, have important effects on cholesterol inhibition in the body. This mechanism is still not completely understood, but there are some hypotheses: cholesterol absorption would be inhibited because of (1) micellar solubilization; (2) co-crystallization of cholesterol and phytosterols from the giant micelles; (3) inhibition of lipases, esterases, and other enzymes that are involved in the sterol absorption process; (4) effects on the activity of brush border transport (Rozner and Garti, 2006). Other beneficial effects of these compounds are the anti-carcinogenic and anti-polymerizing properties in oils rich in unsaturated fatty acids, such as canola oil (Moreau et al., 2002). Despite their nutritional value, the addition of these compounds in food is restricted since in free form they are not miscible in water and have low solubility in fats and oils (Salo and Wester, 2005).

Phytosterols can be used as modifiers on the crystallization and structuring of lipids and to obtain lipid matrices with specific physical properties (Wassell et al., 2010). These changes occur due to different mechanisms: covalent bonds, hydrogen bonds, Van der Waals forces or steric entanglement, causing changes in solid profiles, melting points, consistency and other physical properties in fatty systems (Pernetti et al., 2007). Several types of phytosterols have potential for structuring oils and fats to form a continuous crystal network, resulting in higher consistency for the lipid matrix (Pernetti et al., 2007). The esterification of phytosterols and stanols with long chain fatty acids increases 
their solubility in the lipid phase and consequently facilitates their incorporation into foods, but this process adversely affects the cholesterol-lowering properties of phytosterols, which should preferably be used in their free form for the functional effect (Noakes et al., 2005).

By dispersing phytosterols in the oil phase, it has been possible to maximize the concentration of phytosterols used and maintained in solution in oil over time, but also to achieve easily obtainable dispersion without the need for a step involving the melting of the phytosterols. The resulting products have acceptable organoleptic properties and are suitable for ingestion in the form of diverse oil-based nutritional and pharmaceutical formulations (Auriou, 2004).

$\mathrm{PO}$ is one of the most commonly used fats for food production due to its physical and chemical characteristics. This oil has a high content of palmitic acid, a saturated fatty acid responsible for cardiovascular diseases. With the aim of obtaining a lipid matrix with the required physical and chemical properties for use in fatty based products with hypocholesterolemic properties, a promising approach is the mixture of oils rich in monounsaturated fatty acids and/or other biofunctional compounds with PO.

The aim of this study was to develop a complete characterization of the effect of dispersed free phytosterols (FP) and HSO on the physical properties and crystallization behavior of $\mathrm{PO} / \mathrm{CO}$ blends in order to obtain zero trans-fat lipid blends with reduced levels of saturated fatty acids for application in processed foods. It is possible that FP act as the main nuclei for crystallization and together with HSO can induce the crystallization process, modifying properties such as consistency, microstructure and polymorphism. The addition of $\mathrm{CO}$ in $\mathrm{PO}$ was used to reduce the amount of saturated fatty acids in the blends, producing healthy and applicable lipid systems. At the same time, phytosterols have a recognized hypocholesterolemic effect, which contributes to the reduction in the risk of cardiovascular diseases.

\section{MATERIALS AND METHODS}

\subsection{Materials}

Refined palm oil (PO), supplied by Agropalma (Brazil); Refined canola oil (CO) acquired in a local market; Fully hydrogenated soybean oil (HSO), available from Cargill Agrícola (Brazil); Mixture of free phytosterols (FP), provided by the Cognis company (Brazil) with the following composition: beta-sitosterol (47.4\%); campesterol $(26.2 \%)$; stigmasterol $(14.0 \%)$; brasicasterol $(3.6 \%)$; delta 5-avenasterol $(2.4 \%)$; cholesterol $(0.4 \%)$; campestanol (0.6\%); sitostanol (0.8\%); delta 7-avenasterol $(0.3 \%)$; delta 5 -stigmasterol $(0.5 \%)$; others $(3.8 \%)$.

\subsection{Preparation of blends}

Mixtures of PO and $\mathrm{CO}$ were prepared as reference systems with PO:CO (w:w) ratios of 100:0, 80:20, 60:40, 40:60, 20:80 and 0:100; and identified respectively using the same numerical codes. Two sets of blends were prepared from the reference systems: i) a set added of 10\% (w:w) dispersed FP, identified as 100:0-FP, 80:20-FP, 60:40-FP, 40:60FP, 20:80-FP and 0:100-FP; ii) a set added with $10 \%$ (w:w) dispersed FP and 5\% (w:w) HSO, identified as 100:0-FP-HSO, 80:20-FP-HSO, 60:40-FP-HSO, 40:60-FP-HSO, 20:80-FP-HSO and 0:100-FP-HSO. The oil mixtures were heated to $100{ }^{\circ} \mathrm{C}$, and the structuring agents were added under magnetic stirring. The systems were maintained under agitation for 3 minutes for complete homogenization. This temperature was used because when free phytosterols and stanols are heated at higher temperatures, the formation of dimeric, oligomeric or other oxidation products may occur, according some studies (Raczyk et al. 2017; Senate Commission on Food Safety 2014).

\subsection{Physical and chemical characterization}

\subsubsection{Fatty acid composition}

The fatty acid composition was determined for $\mathrm{PO}, \mathrm{CO}$ and HSO, using a gas chromatographic system, CGC Agilent Series 6850 (Santa Clara, California, USA) with FID detector; capillary column Agilent-DB-23 (50\% cyanopropyl - methylpolysiloxane), length $60 \mathrm{~m}$, internal diameter $0.25 \mathrm{~mm}$ and film thickness $0.25 \mu \mathrm{m}$. The operational conditions were: flow rate of $1.0 \mathrm{ml} / \mathrm{min}$; linear velocity of $24 \mathrm{~cm} / \mathrm{s}$; injector temperature of $250{ }^{\circ} \mathrm{C}$; detector temperature of $280^{\circ} \mathrm{C} / \mathrm{min}$; oven temperature of $110^{\circ} \mathrm{C}$ for $5 \mathrm{~min}, 110-215^{\circ} \mathrm{C}$ at $5^{\circ} \mathrm{C} / \mathrm{min}, 215^{\circ} \mathrm{C}$ for $34 \mathrm{~min}$; helium carrier gas; injected volume of $1.0 \mu \mathrm{L} / \mathrm{min}$ and split of 1:50. Derivatization was performed by methylation using $\mathrm{NH}_{4} \mathrm{Cl}$ in a methanol solution. Methyl esters were extracted using a $\mathrm{NaCl}$ saturated solution and petroleum ether, according to the methodology proposed by Hartman and Lago (1973). Individual fatty acid methyl esters were identified by comparison of retention times to commercial standards, and they were quantified based on relative peak areas. The fatty acid composition of the blends was calculated by weighing the composition $\mathrm{PO}$ and $\mathrm{CO}$ with their respective mass fractions in the mixtures.

\subsection{Atherogenic index}

The Atherogenic Index (AI) can be calculated for diets or foods according to fatty acid composition, the ratio between the sums of lauric, miristic and palmitic acids and unsaturated fatty acids present in the blends (Equation 1). The higher the value found 
for this relationship, more atherogenic is the blend, with greater contribution to the development of cardiovascular diseases like atherosclerosis and thrombosis (Kim et al., 2008; Ulbricht et al., 1991).

$$
\mathrm{AI}=\frac{\mathrm{C} 12: 0+\mathrm{C} 14: 0+\mathrm{C} 16: 0}{\mathrm{C} 18: 1+\mathrm{C} 18: 2+\mathrm{C} 18: 3+\mathrm{C} 16: 1+\mathrm{C} 20: 1}
$$

Equation 1

\subsection{Triacylglycerol composition}

This composition was determined for $\mathrm{PO}, \mathrm{CO}$ and HSO using a gas chromatography CGC Agilent 6850 Series GC System (Santa Clara, California, USA). A capillary column Agilent - DB-17 HT (50\% phenyl- $50 \%$ methylpolysiloxane) was used: length $15 \mathrm{~m}$, internal diameter $0.25 \mathrm{~mm}$ and film thickness $0.15 \mu \mathrm{m}$. The operational conditions were: injector temperature $360{ }^{\circ} \mathrm{C}$; detector temperature of $375{ }^{\circ} \mathrm{C} / \mathrm{min}$; oven temperature from $250^{\circ} \mathrm{C}$ to $350{ }^{\circ} \mathrm{C}$ at $5^{\circ} \mathrm{C} / \mathrm{min}, 350{ }^{\circ} \mathrm{C}$ for $20 \mathrm{~min}$; helium carrier gas; injected volume of $1.0 \mu \mathrm{L} / \mathrm{min}$ and split of 1:100. Triacylglycerols were identified by comparison of retention times, and quantified based on relative peak areas (de Oliveira et al., 2015; Ribeiro et al., 2013). The triacylglycerol compositions of the blends were calculated by weighing the composition $\mathrm{PO}, \mathrm{CO}$ and $\mathrm{HSO}$ with their respective mass fractions in the mixtures in terms of trissaturated $\left(\mathrm{S}_{3}\right)$, dissaturated $\left(\mathrm{S}_{2} \mathrm{U}\right)$, monossaturated $\left(\mathrm{SU}_{2}\right)$ triunsaturated $\left(\mathrm{U}_{3}\right)$ triacylglycerols.

\subsection{Thermal behavior}

The thermal behavior of the blends was evaluated by crystallization curves. The equipment used was a differential scanning calorimeter TA Q 2000 Thermal Analyzer, with the data processing system Universal V4.7a coupled to a RCS90 Refrigerated Cooling System (TA Instruments, Waters LLC). The samples were subjected to the temperature program: $80{ }^{\circ} \mathrm{C}$ for $10 \mathrm{~min}, 80^{\circ} \mathrm{C}$ to $-60^{\circ} \mathrm{C}$ at $10^{\circ} \mathrm{C} / \mathrm{min}$, $-60^{\circ} \mathrm{C}$ for 30 min. (AOCS, 2009; Campos, 2005).

\subsection{Consistency}

The consistency of the blends was assessed using the texture analyzer TA-XT2i plus equipment (Stable Micro Systems). The samples were heated for complete melting and stored in $50 \mathrm{~mL}$ beakers. The conditioning of the samples was performed in an incubator using a pre-stabilization step of $24 \mathrm{~h}$ at $5{ }^{\circ} \mathrm{C}$, and a stabilization step of $24 \mathrm{~h}$ at $15^{\circ} \mathrm{C}$. The tests were performed in quadruplicate at $15^{\circ} \mathrm{C}$, using a probe Plexiglas $60^{\circ}$ angle cone with a nontruncated tip. The experiments were carried out at a distance of $10 \mathrm{~mm}$, velocity of $2 \mathrm{~mm} / \mathrm{s}$ and time of $5 \mathrm{~s}$ (Campos, 2005; Oliveira et al., 2015). The compression force was given in gf, and the penetration data were converted to yield value according to Haighton, 1959, as described by the equation 2:

$$
\mathrm{YV}=\frac{\mathrm{K} \times \mathrm{W}}{\mathrm{P}^{1,6}}
$$

Equation 2

where $\mathrm{YV}$ is yield value $\left(\mathrm{gf} / \mathrm{cm}^{2}\right) ; \mathrm{K}$ is a factor depending on the cone angle ( 2815 for $60^{\circ}$ angle); W is the compression force ( $\mathrm{gf}) ; \mathrm{p}$ is penetration depth $(0.1 \mathrm{~mm})$.

\subsection{Solid fat content}

The solid fat content (SFC) as a function of temperature was determined by a low resolution NMR spectrometer (Bruker pc 120 Minispec). The temperature was controlled using high precision dry baths (TCON 2000, $0-70^{\circ} \mathrm{C}$ ). The analyses were carried out according to the AOCS Cd 16b-93 (AOCS, 2009) direct method, following sequential measurements at temperatures of $10,15,20,25,30$, $35,40,45$ and $50^{\circ} \mathrm{C}$.

\subsection{Microstructure}

The samples were heated to $80{ }^{\circ} \mathrm{C}$, and a drop was placed on a pre-heated glass slide with the aid of a glass capillary tube covered with a preheated $\left(80^{\circ} \mathrm{C}\right)$ coverslip. Slides in triplicate were maintained at $25{ }^{\circ} \mathrm{C}$ for $2 \mathrm{~h}$ in an incubator. After this period, the morphology of crystal agglomerates was assessed using light polarized microscopy (Olympus, model B50) coupled to a digital video camera (Media Cybernetics). The slides were transferred onto a temperature-controlled plate $\left(25^{\circ} \mathrm{C}\right)$. The images were taken from three different visual fields, at a magnification of $40 \mathrm{X}$, and then, a single representative image was selected to represent the systems (Campos, 2005). The software Image Pro Plus (version 7.0, Media Cybernetics) was used to take the images.

\subsection{Polymorphism}

The crystalline polymorphic form of the blends was determined according to the AOCS $\mathrm{Cj}$ 2-95 methodology (AOCS, 2009). The analyses were performed in a diffractometer (Philips PW 1710); Bragg-Brentano geometry $(\theta: 2 \theta)$; $\mathrm{Cu}-\mathrm{Ka}$ radiation $(\mathrm{k}=1.54056 \AA$; at $40 \mathrm{kV}$ and $30 \mathrm{~mA})$. The assays were carried out with a 0.02 step in $2 \theta$, for an acquisition time of 2 seconds, over the range $5-40^{\circ}$ ( $2 \theta$ scale). The tests were performed at $15^{\circ} \mathrm{C}$, after melting and storage of the samples for 30 days at this temperature. The crystalline forms were identified from their characteristic short spacings, calculated using the Bragg Law: 


$$
\lambda=2 \mathrm{~d} \operatorname{sen} \theta
$$

Where $\lambda$ is the wavelength emitted $\mathrm{X}$-ray, $\mathrm{d}$ is the short spacing and $\theta$ is the diffraction angle.

\section{RESULTS AND DISCUSSION}

\subsection{Chemical composition}

PO composition showed about $4 \%$ more unsaturated fatty acid compared to the saturated ones, while unsaturated fatty acids $(62.8 \%$ monounsaturated) represented about 10.5 times more than saturated molecules in $\mathrm{CO}$, as shown in Table 1. HSO did not present significant amounts of unsaturated fatty acids, with $87.2 \%$ total acid content composed for stearic acid due to full hydrogenation of oleic, linoleic and linolenic acids from natural soybean oil.

The saturated fatty acid contents of the control systems compared to those added with 5\% HSO increased from $48.18-8.71 \%(100: 0-0: 100)$ to 50.77 - 13.27\% (100:0-FP-HSO - 0:100-FP-HSO). Stearic acid content increased from $4.96-2.57 \%$ to $9.07-6.8 \%$, while oleic acid decreased from $41.76 \%$ $-61.35 \%$ to $39.68-58.29 \%$, respectively for $100: 0$ - 0:100 and 100:0-FP-HSO - 0:100-FP-HSO. The blends containing both $\mathrm{PO}$ and $\mathrm{CO}$ resulted in intermediate values of these compounds. In this way, the addition of HSO resulted in increases in stearic acid contents of 1.8 and 2.7 times, respectively, for the systems with no addition of $\mathrm{CO}$ and no addition of PO.

The results for fatty acid composition showed that it was possible to reduce the saturated fatty acids in the control blends by $39.7 \%$; while there was an increase of $20.7 \%$ in monounsaturated fatty acids and $18.7 \%$ in polyunsaturated fatty acids. For blends containing HSO these reductions corresponded to $37.5 \%, 19.7 \%$ and $18.7 \%$, respectively.

The systems containing 5\% HSO showed a constant increase, as a function of the PO content, $2.05 \%$ of $\mathrm{S}_{3}$, as observed in Table 2. On the other hand, the same system showed a decrease in $\mathrm{U}_{3}$ as a function of $\mathrm{PO}$ addition in the range of $13-14 \%$. The mixtures added with HSO, had from about 3.3 to 1.5 times more $S_{3}$, following the increase in palm oil addition, compared to those with no addition of HSO.

Systematic reviews indicate that Intake replacement of saturated fatty acids by unsaturated fatty acids may reduced the incidence of cardiovascular diseases (de Souza et al., 2015) and the consumption of $2 \mathrm{~g}$ /day of phytosterols decreases LDL cholesterol concentration on average by 10\% (Brufau et al., 2008). Regarding the possible application of these blends, an effective portion to reduce cholesterol levels should contain $20 \mathrm{~g} /$ day of the blend. In margarines, for example, formed by $80 \%$ of the lipid phase, about $25 \mathrm{~g}$ of the final product, equivalent to approximately one tea spoon should be consumed per day to ensure its funtional effect.
The metodology used for evaluating chemical composition did not cover the investigation of minor lipids in the blends. However, $\mathrm{CO}$ and PO were refined and newly acquired for this study, thereby minimizing the presence of partial acylglycerols in the evaluated blends.

\subsection{Atherogenic index}

The intake of foods with large amounts of cholesterol and saturated fats favors the development of cardiovascular diseases. These considerations, along with an increased awareness among the public, led to the development of a single number to express the hypercholesterolaemic atherogenic potential of various foods through their fatty acid compositions (Connor et al., 1986). This index allows a comparison of the influence of different oil/fat compositions on the development of coronary diseases. The AI can be calculated by the ratio between the sum of lauric, myristic and palmitic acids and the sum of linoleic, linolenic and monounsaturated acids. Higher values of AI indicate higher possibilities for the development of coronary diseases (Kim et al., 2008; Ulbrich, Southgate., 1991). AI increased from 0.0509 to 0.8210 and from 0.0571 to 0.8318 as a result of the increase in PO contents for the systems with and without HSO, respectively, as shown in Table 3. AI increased from 1 to $12 \%$, due to the addition of $5 \%(\mathrm{w} / \mathrm{w}) \mathrm{HSO}$ to the blends, indicating a very low change in this parameter for systems with higher fractions of PO. The blends with higher contents of $\mathrm{CO}$ were characterized for low values of IA, indicating no negative impact on health.

\subsection{Solid fat content}

Figures 1 and 2 show the increase in the SFC of the systems over the whole temperature range evaluated, due to the addition of FP in the mixtures containing $\mathrm{PO}$ and $\mathrm{CO}$ and the addition of HSO to the mixtures containing $\mathrm{PO}, \mathrm{CO}$, and FP.

FP had a structuring effect on the lipid systems which allowed a similar or higher SFC for blends with lower saturated fat acid contents. Nutritionally, this is a very beneficial effect since saturated fats, presenting negative effects on human health, are substituted by a functional class of compounds with high nutritional value. Similarly, HSO had a positive effect on the increase in SFC for systems added with FP. Although HSO is composed of saturated fatty acids, the addition of small fractions of this component enabled the substitution of higher amounts of PO, which contains high amounts of palmitic acid, to obtain a similar solid profile and diminish the final content of saturated fatty acids in the blends.

The solid profile is directly related to the selection of lipid systems for use in lipid food based products. At low temperatures $\left(4-10{ }^{\circ} \mathrm{C}\right)$, this parameter 


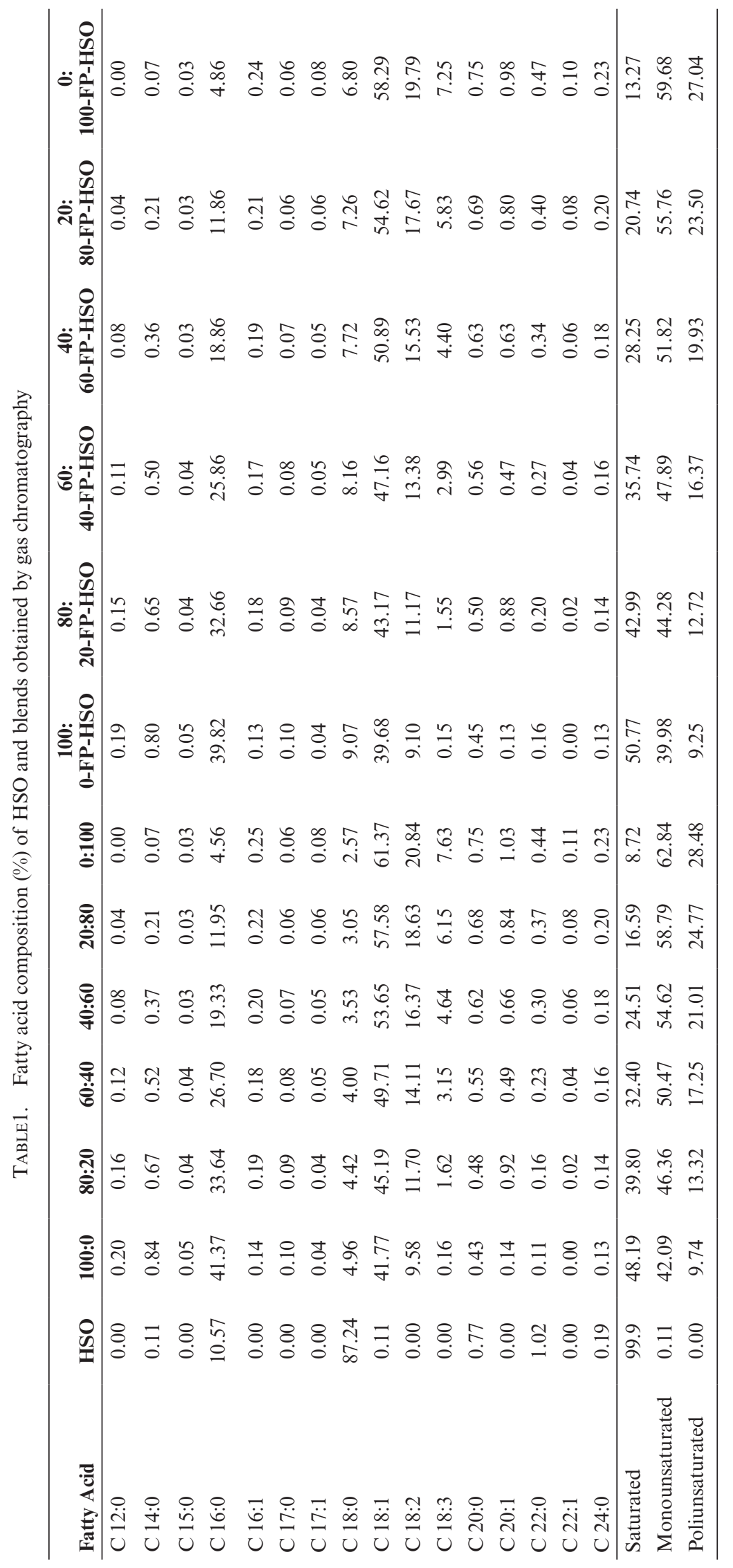


TABLE 2. Triacylglycerol classes ( $\%$ ) of the blends.

\begin{tabular}{lcccc}
\hline Blends & $\mathbf{S}_{\mathbf{3}}$ & $\mathbf{S}_{\mathbf{2}} \mathbf{U}$ & $\mathbf{S U}_{\mathbf{2}}$ & $\mathbf{U}_{\mathbf{3}}$ \\
\hline $100: 0$ & 10.79 & 35.80 & 39.03 & 14.38 \\
$80: 20$ & 8.63 & 28.64 & 33.86 & 28.87 \\
$60: 40$ & 6.47 & 21.48 & 28.69 & 43.36 \\
$40: 60$ & 4.32 & 14.32 & 23.52 & 57.84 \\
$20: 80$ & 2.16 & 7.16 & 18.35 & 72.33 \\
0:100 & 0.00 & 0.00 & 13.18 & 86.82 \\
100:0-FP-HSO & 15.25 & 34.01 & 37.08 & 13.66 \\
$80: 20-F P-H S O$ & 13.20 & 27.21 & 32.17 & 27.42 \\
60:40-FP-HSO & 11.15 & 20.41 & 27.26 & 41.19 \\
40:60-FP-HSO & 9.10 & 13.60 & 22.34 & 54.95 \\
20:80-FP-HSO & 7.05 & 6.80 & 17.43 & 68.72 \\
0:100-FP-HSO & 5.00 & 0.00 & 12.52 & 82.48 \\
\hline
\end{tabular}

PO: Palm oil, CO: canola oil. FP: Free Phytosterols; HSO: Hardfat of soybean oil. Blends: PO:OC (w:w): 100:0, 80:20, $60: 40,40: 60,20: 80$ and $0: 100$, added $10 \%$ of FP denominated 100:0FP, 80:20FP, 60:40FP, 40:60FP, 20:80FP, 0:100FP.; U3: trissaturated triacylglycerols; S2U: dissaturated triacylglycerols; SU2: monossaturated triacylglycerols; U3: triunsaturated triacylglycerols.

TABLE 3. Atherogenic index calculated from the ratio between the sums of lauric, miristic and palmitic acids and unsaturated fatty acids present in the blends (Kim et al., 2008; Ulbricht et al., 1991).

\begin{tabular}{lc}
\hline Blends & AI \\
\hline 100:0 & 0.82 \\
$80: 20$ & 0.57 \\
$60: 40$ & 0.40 \\
$40: 60$ & 0.26 \\
$20: 80$ & 0.14 \\
$0: 100$ & 0.05 \\
100:0-FP-HSO & 0.83 \\
80:20-FP-HSO & 0.58 \\
60:40-FP-HSO & 0.41 \\
40:60-FP-HSO & 0.26 \\
20:80-FP-HSO & 0.15 \\
0:100-FP-HSO & 0.05 \\
\hline
\end{tabular}

PO: Palm oil, CO: canola oil. FP: Free Phytosterols; HSO: Hard fat of Soybean Oil Blends: PO:CO (w:w): 100:0, 80:20, 60:40, 40:60, 20:80 and $0: 100,10 \%$ of FP added denominated 100:0FP, 80:20FP, 60:40FP, 40:60FP, 20:80FP, 0:100FP.

determines the use of these systems in products kept under refrigeration, in which the maximum value of SFC is $32 \%$ at $10{ }^{\circ} \mathrm{C}$ for proper spreadability (Wassel; Young, 2007). The blends used for this purpose could be 60:40 and 40:60, 60:40-FP and 40:60FP and 60:40-FP-HSO and 40:60-FP-HSO. From $20-22{ }^{\circ} \mathrm{C}$, SFC higher than $10 \%$ is essential to the physical stability of the products and to avoid oil exudation (Wassel; Young, 2007). Thus the blends meeting this requirement could be 60:40-FP, 80:20FP, 100:0-FP, 40:60-FP-HSO, 60:40-FP-HSO, 80:20-FP-HSO and 100:0-FP-HSO. Considering that SFC at temperatures around $35{ }^{\circ} \mathrm{C}$ has a significant effect on properties like flavor release, softness and thermal resistance, the blends 60:40-FP, 80:20-FP, 100:0-FP and all blends containing HSO had more than $4 \%$ SFC, in contrast to the blends composed only of CO and PO, in which SFC was even lower than this value (Ribeiro et al., 2013).

For application in processed foods, the structured blends composed of PO/OC added with FP or HSO may be indicated for use in margarine and spreads even with $4 \% \mathrm{SFC}$, because this shows more than $30 \% \mathrm{SFC}$ at $10{ }^{\circ} \mathrm{C}$ and less tan $5 \% \mathrm{SFC}$ at 30 ${ }^{\circ} \mathrm{C}$. The curve charateristics of the decrease in solids shows a more plastic consistency with slow melting and no waxy sensation. Possible mouthfeel (bitterness, texture, grainy feel) related to phytosterols can be minimized in emulsified systems. Furthermore, in processed products the structured blends would be incorporated as ingredients of the formulation, effectively reducing the possibility of sensory defects (Metzroth, 2015).

\subsection{Consistency}

The yield value (YV) increased as a function of PO addition to the blends, as observed in Figure 3. For blends composed of only $\mathrm{CO}$ and PO, contents lower than $40 \% \mathrm{CO}$ resulted in yield values lower than the texture analyzer sensibility due to high fractions in the liquid phase. The addition of $10 \%$ FP resulted in a high increase, from 1.5 to 4.3 times for $\mathrm{YV}$, resulting in a value of $28.4 \mathrm{~g} / \mathrm{cm}^{2}$ or a blend with $20 \%$ PO. The addition of $5 \% \mathrm{HSO}$ decreased the YV for the blends added with FP containing $100 \%$ and $80 \%$ PO, causing a mechanical weakness in the crystal network structure formed.

Correlating the YV with the SFC of the blends, strong exponential correlations were observed. These correlations were described by $\mathrm{YV}=20.443^{0.1426} \mathrm{SFC}$ $\left(\mathrm{R}^{2}=0.9788\right), \mathrm{YV}=19,393^{0.171 \cdot \mathrm{SFC}}\left(\mathrm{R}^{2}=0.9080\right)$ and $\mathrm{YV}=20,16^{0.1565 \cdot \mathrm{SFC}}\left(\mathrm{R}^{2}=0.9054\right)$, respectively, for blends the addition of FP and HSO, the addition of FP and composed of only PO and CO. This behavior indicates that the resistance of the structure formed in the blends is strongly affected by SFC.

It was possible to improve the consistency of the fatty systems by adding only FP, obtaining similar or better results compared to the addition of FP and HSO, as can be observed from the YV for both types of systems. The use of only FP is nutritionally advantageous since it replaces saturated fatty acids and presents a set of health benefits. 


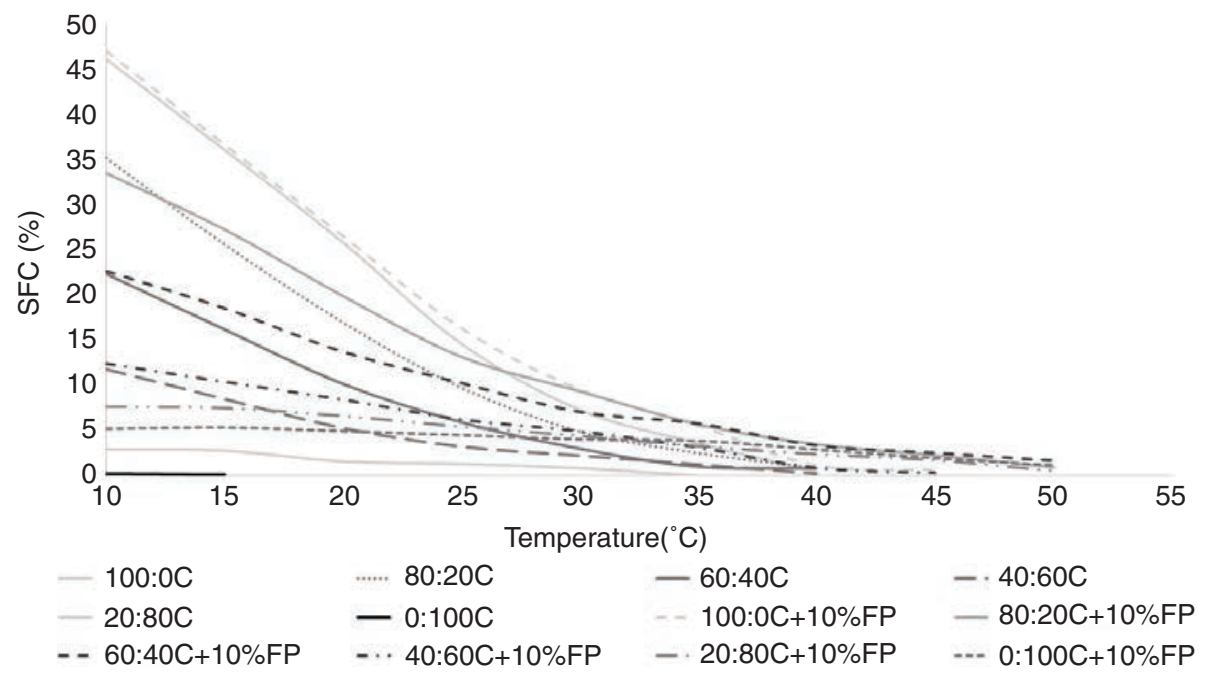

FIGURE 1. Solid fat content of lipid blends (100:0C, 80:20C, 60:40C, 40:60C, 20:80C, 0:100C) with the addition of phytosterols $(100: 0 \mathrm{C}+10 \% \mathrm{FL}, 80: 20 \mathrm{C}+10 \% \mathrm{FL}, 60: 40 \mathrm{C}+10 \% \mathrm{FL}, 40: 60 \mathrm{C}+10 \% \mathrm{FL}, 20: 80 \mathrm{C}+10 \% \mathrm{FL}, 0: 100 \mathrm{C}+10 \% \mathrm{FL})$ for temperatures from $10{ }^{\circ} \mathrm{C}$ to $50{ }^{\circ} \mathrm{C}$ (complete melting).

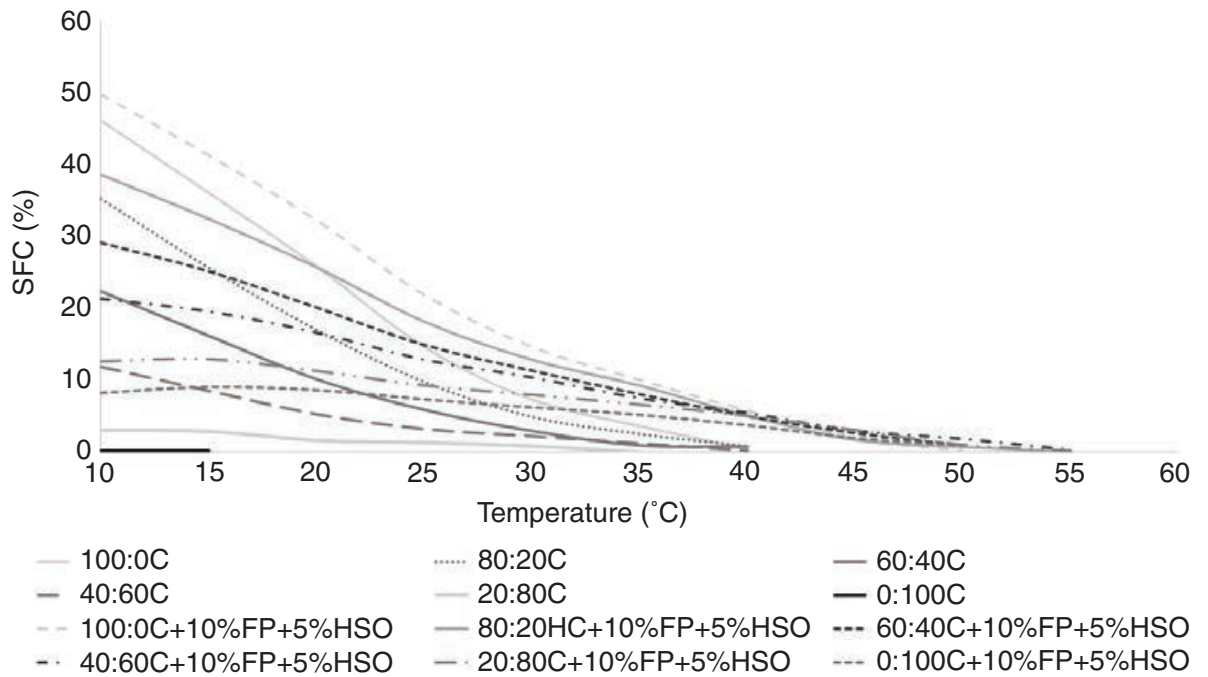

FIGURE 2. Solid fat content of lipid blends (100:0C, 80:20C, 60:40C, 40:60C, 20:80C, 0:100C) and addition of phytosterols and fully hydrogenated soybean oil (and addition of phytosterols $(100: 0 \mathrm{C}+10 \% \mathrm{FL}, 80: 20 \mathrm{C}+10 \% \mathrm{FL}, 60: 40 \mathrm{C}+10 \% \mathrm{FL}, 40: 60 \mathrm{C}+10 \% \mathrm{FL}$, $20: 80 \mathrm{C}+10 \% \mathrm{FL}, 0: 100 \mathrm{C}+10 \% \mathrm{FL}$ ) for temperatures from $10{ }^{\circ} \mathrm{C}$ to $50{ }^{\circ} \mathrm{C}$ (complete melting).

\subsection{Microstructure}

The formation of crystal structures was observed for all blends having a minimum PO content of $40 \%$, as observed in Figure 4. A lower ratio between $\mathrm{PO}$ and $\mathrm{CO}$ resulted in the absence of crystallinity or in some few scattered structures, no formation of a crystal network. The microstructure of reference blends, composed of only PO and CO, showed crystal agglomerates with spherulitic form and increased crystal size as a function of the fraction of $\mathrm{CO}$ in the blends. On the other hand, the amount of crystals was opposite to the unsaturated fatty acid content. Spherulites are formed due to crystal lamellae aggregation raising radially from the nuclei, with possible formation of branches with increasing size (Rousset, 2002). High size structures in systems containing high liquid fractions are the result of higher critical size of agglomerates since structures with lower sizes are not stable in this type of systems.

The FP addition resulted in the formation of a large amount of crystal structures with lower sizes than those in reference blends. The lower sizes are possibly related to the distribution of the 


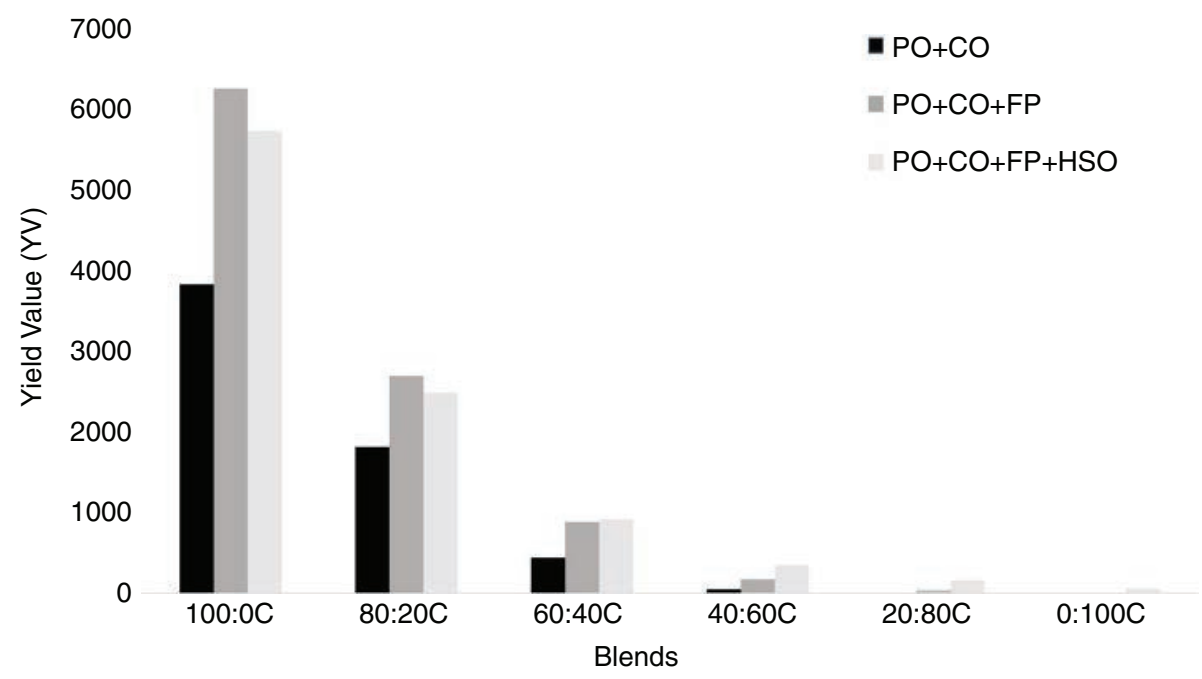

FIGURE 3. Consistency of the blends obtained through Campos methodology (2005) presented according to Yield value calculated by the Haighton equation (1959).

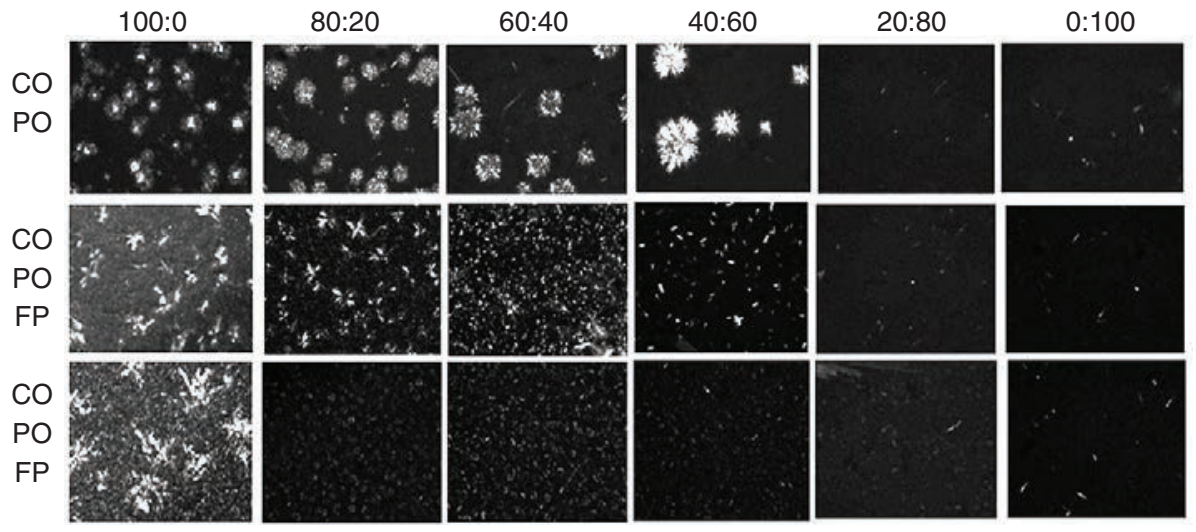

Figure 4. Crystalline networks of control blends $(\mathrm{CO}+\mathrm{PO})$, blends added with free phytosterols $(\mathrm{CO}+\mathrm{PO}+\mathrm{FP})$ and free phytosterols and fully hydrogenated soybean oil ( $\mathrm{CO}+\mathrm{PO}+\mathrm{FP}+\mathrm{HSO})$ obtained after maintaining at $25^{\circ} \mathrm{C}$ for $2 \mathrm{~h}$ at a magnification of $40 \mathrm{X}$ (Campos, 2005)

triacylglycerols with higher melting points among the several crystal agglomerates formed by the FP added to the systems. By increasing the content of $\mathrm{CO}$ of the mixtures, lower melting point triacylglycerols are solubilized, leaving $\mathrm{FP}$ and $\mathrm{S}_{3}$ triacylglycerols. The addition of HSO to the blends contributed to diminishing the crystal size of agglomerates and to raising the amount of crystal structures formed because high melting point material was introduced into the blends.

Sterols and sterol esters generally crystallize into bilayers roughly $4 \mathrm{~nm}$ thick. $\beta$-sitosterol, the major component of evaluated FP, has three known crystal forms: anhydrous crystals, hemi-hydrate crystals ( $1 \mathrm{~mol}$ of water to $2 \mathrm{~mol}$ of $\beta$-sitosterol) and mono-hydrate crystals (1 mol of water to $1 \mathrm{~mol}$ of $\beta$-sitosterol). These cristalline forms can change according to temperature, because the increase in temperature results in a progressive dehydration of the crystals and the network is formed by fitting both molecules on top of each other, making it possible for the stacking to involve van der Walls interation (Bot and Agterof, 2006; Co and Marangoni, 2012).

Both effects of FP and HSO on the microstructure of the systems are in agreement with the increase in YV of the blends. The large amount of agglomerates formed resulted in a dense crystal network with higher mechanical resistance, shown by higher consistency. Smaller agglomerates have greater superficial area, contributing to the formation of a large number of sites for binding among the crystals (Campos, 2005).

Despite being a study aimed at the application of lipid bases in foods, no evaluation of the impact of temperature variation on the microstructure and the formation of crystals was carried out. 


\subsection{Thermal behavior}

The crystallization behavior of PO:CO blends was characterized by two main peaks (peak 1 and peak 2) as shown in Table 4 and Figures 5 to 10. The first one is a result of the high melting point compounds, $\mathrm{S}_{3}$ and $\mathrm{SU}_{2}$ and the second one corresponds to a mixture of monounsaturated and $\mathrm{S}_{2} \mathrm{U}$. A third peak, mainly related to a fraction of $\mathrm{U}_{3}$, was observed at temperatures lower than $-54^{\circ} \mathrm{C}$. The diminishing of peak 1 and peak 2 as a function of $\mathrm{CO}$ addition is a result of the increase

TABLE 4. Thermal behavior parameters in crystallization obtained by differential scanning calorimeter (AOCS, 2009; Campos, 2005)

\begin{tabular}{lcccccccc}
\hline Samples & $\mathbf{T}_{\text {initial }}\left({ }^{\circ} \mathbf{C}\right)$ & $\mathbf{T}_{\text {peak } 1}\left({ }^{\circ} \mathbf{C}\right)$ & $\mathbf{T}_{\text {peak } 2}\left({ }^{\circ} \mathbf{C}\right)$ & $\mathbf{T}_{\text {peak } \mathbf{3}}\left({ }^{\circ} \mathbf{C}\right)$ & $\mathbf{T}_{\text {final }}\left({ }^{\circ} \mathbf{C}\right)$ & $\Delta \mathbf{H}_{\mathbf{1}}(\mathbf{J} / \mathbf{g})$ & $\Delta \mathbf{H}_{\mathbf{2}}(\mathbf{J} / \mathbf{g})$ & $\Delta \mathbf{H}_{\mathbf{3}}(\mathbf{J} / \mathbf{g})$ \\
\hline 100:0C & 19.38 & 18.11 & 1.31 & -51.51 & -59.12 & 9.91 & 46.25 & 1.93 \\
20:80C & 6.29 & 3.32 & -12.87 & -58.91 & -59.55 & 2.14 & 11.28 & 1.66 \\
40:60C & 12.33 & 10.49 & -7.22 & -59.14 & -59.69 & 4.01 & 16.83 & 3.86 \\
60:40C & 15.49 & 13.82 & -4.11 & -57.17 & -59.55 & 6.02 & 24.7 & 3.59 \\
80:20C & 17.65 & 16.25 & -1.11 & -53.83 & -59.26 & 8.03 & 34.82 & 2.35 \\
0:100C & -13.26 & -18.67 & -59.02 & - & -59.55 & 5.86 & 1.30 & - \\
100:0FP & 18.23 & 16.06 & -1.84 & -59.68 & -60.13 & 7.41 & 26.57 & 0.44 \\
20:80FP & 8.31 & 3.56 & -14.44 & -59.66 & -59.84 & 1.37 & 6.96 & 0.52 \\
40:60FP & 12.62 & 9.99 & -10.53 & -59.69 & -59.98 & 3.08 & 14.30 & 0.43 \\
60:40FP & 16.36 & 12.07 & -7.12 & -59.88 & -59.98 & 4.31 & 16.33 & 1.89 \\
80:20FP & 17.51 & 13.82 & -5.11 & -59.83 & -59.25 & 6.24 & 21.01 & 1.21 \\
0:100FP & -13.69 & -19.31 & -54.23 & - & -59.00 & 0.87 & 5.05 & - \\
100:0 FP - HSO & 37.20 & 24.14 & -0.95 & -59.67 & -59.98 & 11.68 & 26.56 & 0.44 \\
20:80 FP - HSO & 38.21 & 24.91 & -13.61 & -59.84 & -60.13 & 5.86 & 7.44 & 1.49 \\
40:60 FP - HSO & 34.62 & 25.29 & -9.58 & -59.89 & -60.15 & 9.04 & 11.66 & 1.70 \\
60:40 FP - HSO & 36.92 & 24.22 & -6.16 & -59.83 & -60.13 & 9.89 & 16.69 & 1.18 \\
80:20 FP - HSO & 32.31 & 23.85 & -3.91 & -59.80 & -59.98 & 10.64 & 20.83 & 1.09 \\
0:100 FP - HSO & 35.48 & 24.75 & -38.18 & -59.82 & -60.11 & 5.31 & 2.86
\end{tabular}

Blends: PO:OC (w:w): 100:0, 80:20, 60:40, 40:60, 20:80 and 0:100, 10\% added FP denominated 100:0FP, 80:20FP, 60:40FP, 40:60FP, 20:80FP, 0:100FP. PO: Palm oil, CO: canola oil. Tinitial $\left({ }^{\circ} \mathrm{C}\right)$ : Initial temperature of crystallization; T peak $1\left({ }^{\circ} \mathrm{C}\right)$ : Temperature of peak 1; T peak $2\left({ }^{\circ} \mathrm{C}\right)$ : Temperature of peak 2 ; T peak $3\left({ }^{\circ} \mathrm{C}\right)$ : Temperature of peak 3 ; T final $\left({ }^{\circ} \mathrm{C}\right)$ : Final temperature of crystallization. $\Delta \mathrm{H} 1$ $(\mathrm{J} / \mathrm{g})$ : Enthalpy of Peak 1; $\Delta \mathrm{H} 2(\mathrm{~J} / \mathrm{g})$ : Enthalpy of peak $2 ; \Delta \mathrm{H} 3(\mathrm{~J} / \mathrm{g})$ : Enthalpy of peak 3.

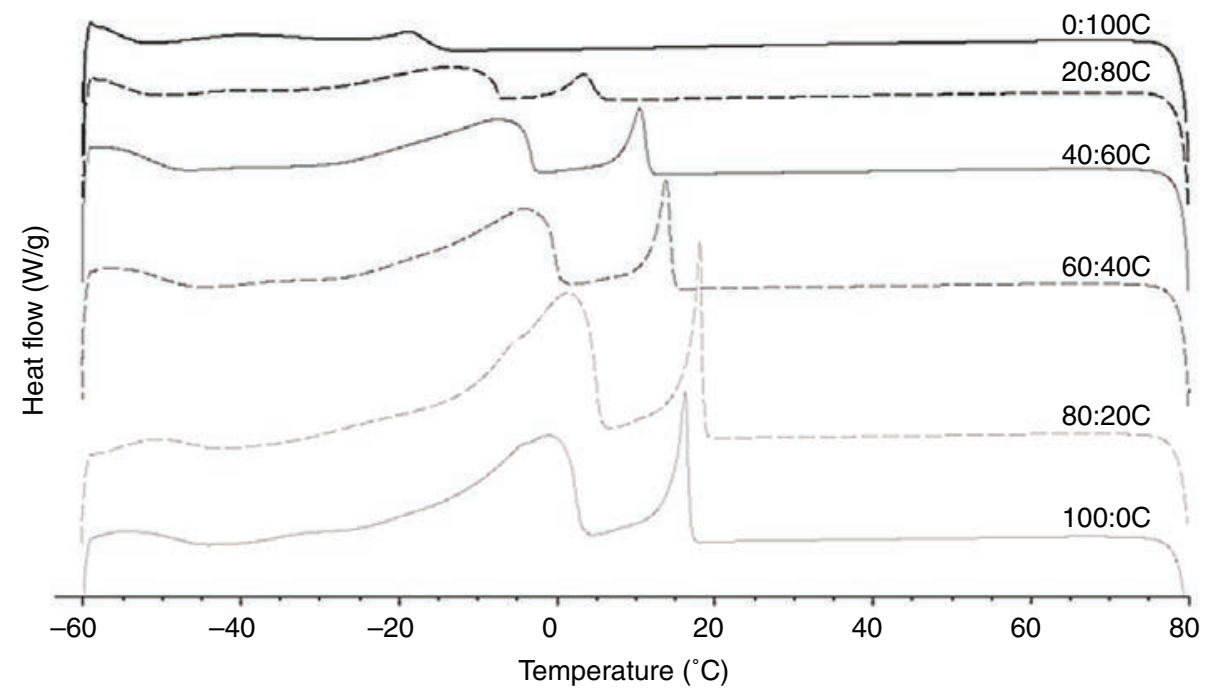

Figure 5. Crystalization behavior for the control blends (100:0C, 80:20C, 60:40C, 40:60C, 20:80C, 0:100C). 


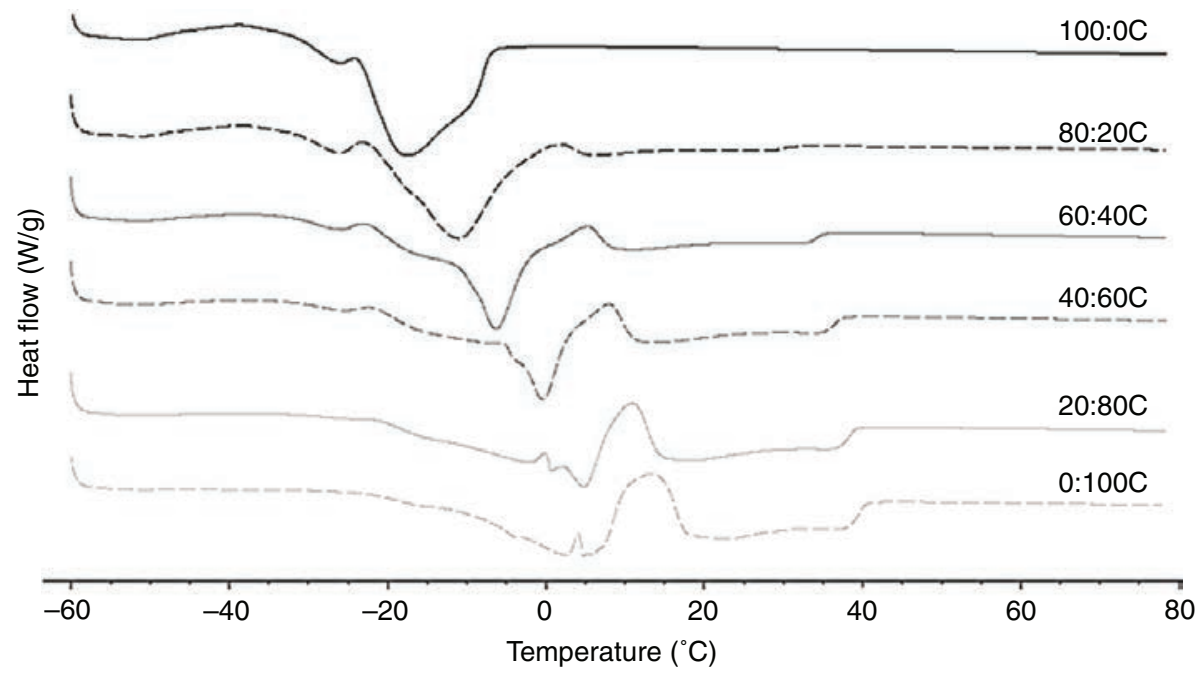

Figure 6. Melting behavior for the control blends (100:0C, 80:20C, 60:40C, 40:60C, 20:80C, 0:100C).

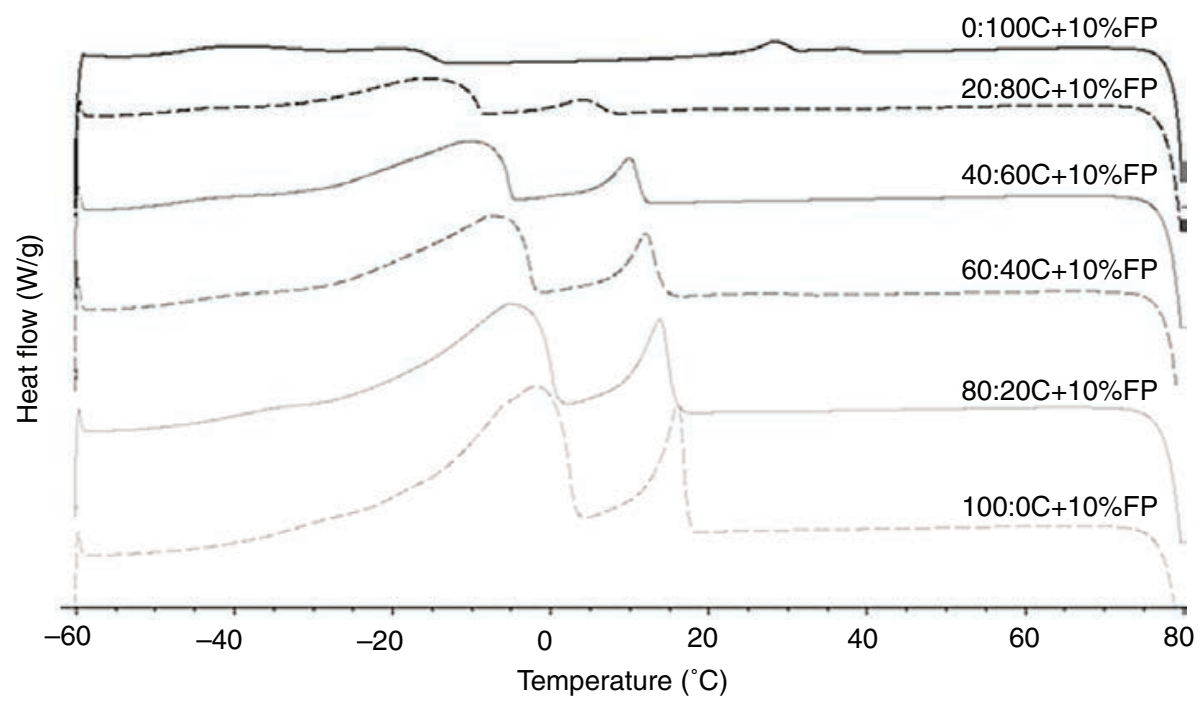

FIGURE 7. Crystalization behavior for the blends added with $10 \%$ free phytosterols $(100: 0 \mathrm{C}+10 \% \mathrm{FL}, 80: 20 \mathrm{C}+10 \% \mathrm{FL}$, $60: 40 \mathrm{C}+10 \% \mathrm{FL}, 40: 60 \mathrm{C}+10 \% \mathrm{FL}, 20: 80 \mathrm{C}+10 \% \mathrm{FL}, 0: 100 \mathrm{C}+10 \% \mathrm{FL})$.

in $\mathrm{U}_{3}$ and consequent decrease in the content of compounds crystallizing at this temperature range.

For the systems without PO, the FP addition caused a shifting of the peak 1 from $-18.67^{\circ} \mathrm{C}(0: 100)$ to $28.11^{\circ} \mathrm{C}(0: 100-\mathrm{FP})$. Observing all other blends, the presence of FP, in general terms, did not modify their crystallization profile. The low effect on crystallization profile of these blends is due to the high melting point of $\mathrm{FP}$, about $140{ }^{\circ} \mathrm{C}$ for $\mathrm{FP}$, and their low solubility in fatty systems, $2-5 \%\left(25-50{ }^{\circ} \mathrm{C}\right)$ in corn oil, according to data reported by Vaikousi et al., 2007. Once the solubilized FP co-crystallize with triacylglycerols, and they are mainly responsible for the modification of the crystallization behavior of the systems. In these blends, a great fraction of these compounds was probably not solubilized, thus causing little effect on the thermal behavior of the fatty mixtures.

On the other hand, the addition of HSO modified the crystallization profile of all the blends. The initial crystallization temperatures and the temperatures of peak 1, different for each system with no addition of HSO, changed in about the same 


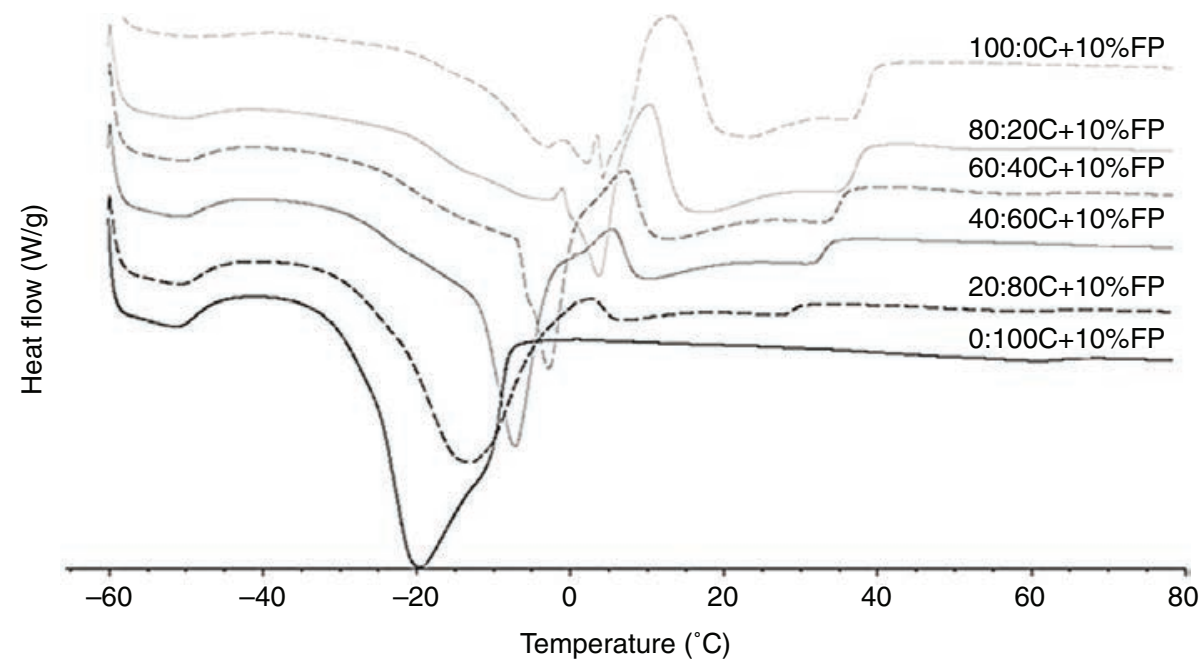

FIGURE 8. Melting behavior for the blends added with 10\% free phytosterols $(100: 0 \mathrm{C}+10 \% \mathrm{FL}, 80: 20 \mathrm{C}+10 \% \mathrm{FL}, 60: 40 \mathrm{C}+10 \% \mathrm{FL}$, $40: 60 \mathrm{C}+10 \% \mathrm{FL}, 20: 80 \mathrm{C}+10 \% \mathrm{FL}, 0: 100 \mathrm{C}+10 \% \mathrm{FL})$.

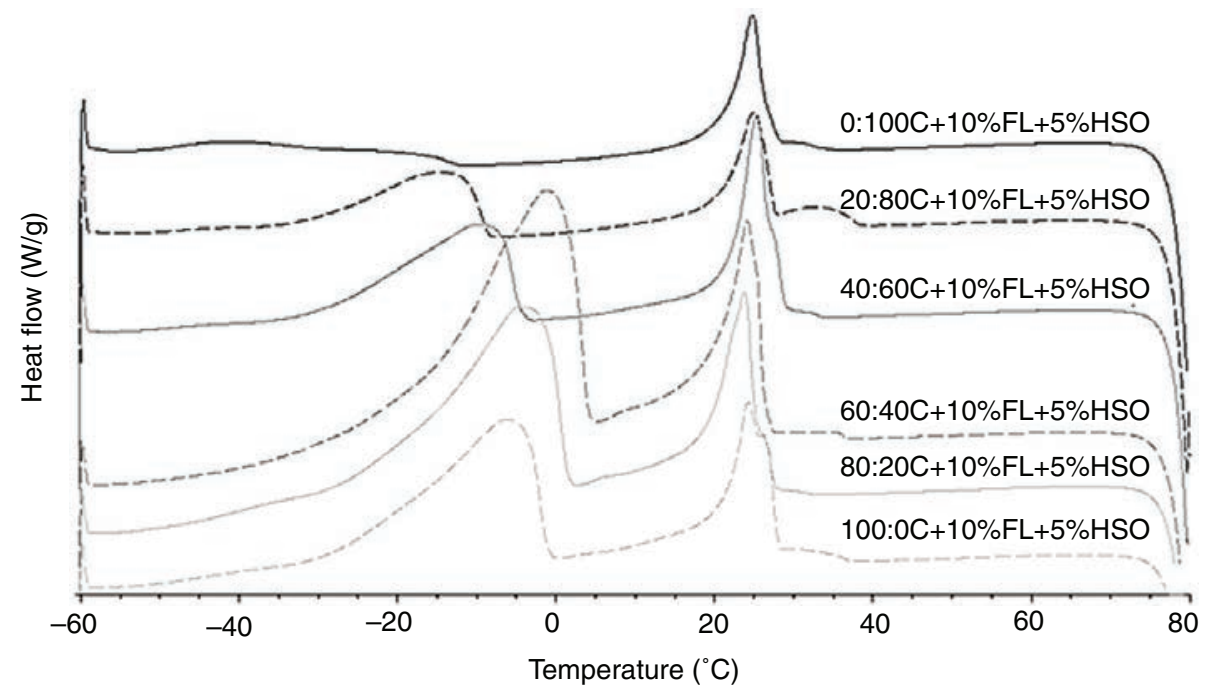

FIGURE 9. Crystalization behavior for the blends added with $10 \%$ free phytosterols and 5\% hydrogenated soybean oil (100:0C + $10 \% \mathrm{FL}+5 \% \mathrm{HSO}, 80: 20 \mathrm{C}+10 \% \mathrm{FL}+5 \% \mathrm{HSO}, 60: 40 \mathrm{C}+10 \% \mathrm{FL}+5 \% \mathrm{HSO}, 40: 60 \mathrm{C}+10 \% \mathrm{FL}+5 \% \mathrm{HSO}, 20: 80 \mathrm{C}+10 \% \mathrm{FL}+$ $5 \% \mathrm{HSO}, 0: 100 \mathrm{C}+10 \% \mathrm{FL}+5 \% \mathrm{HSO})$

temperature range, respectively, from $32.3-38.2^{\circ} \mathrm{C}$ and $24.1-25.2^{\circ} \mathrm{C}$, which was determined by the melting temperature of the HSO. The $\Delta \mathrm{H}$ for peak 1 also was higher than for the blends with no addition of HSO, since HSO added to the systems crystallizes at this temperature range.

In general, the addition of FP into the systems did not cause changes in the crystallization profile of the blends. On the other hand, HSO addition caused displacement at the end of the crystallization process to higher temperature ranges. In addition, a peak at a higher temperature range was observed even for blends with high contents of CO. These two effects are the result of the introduction of $S_{3}$ with high melting points.

\subsection{Polymorphism}

The X-ray diffraction of the reference blends (with no addition of FP), presented characteristic $\beta^{\prime}$-form profile, with short spacings of about 3.8 and $4.2 \AA$ for blends containing from 100 to $60 \%$ PO, while for systems with higher contents of $\mathrm{CO}$, no crystallinity was obtained, as showed in Table 5 and Figure 11. These polymorphs are result of the crystallization of high melting point 


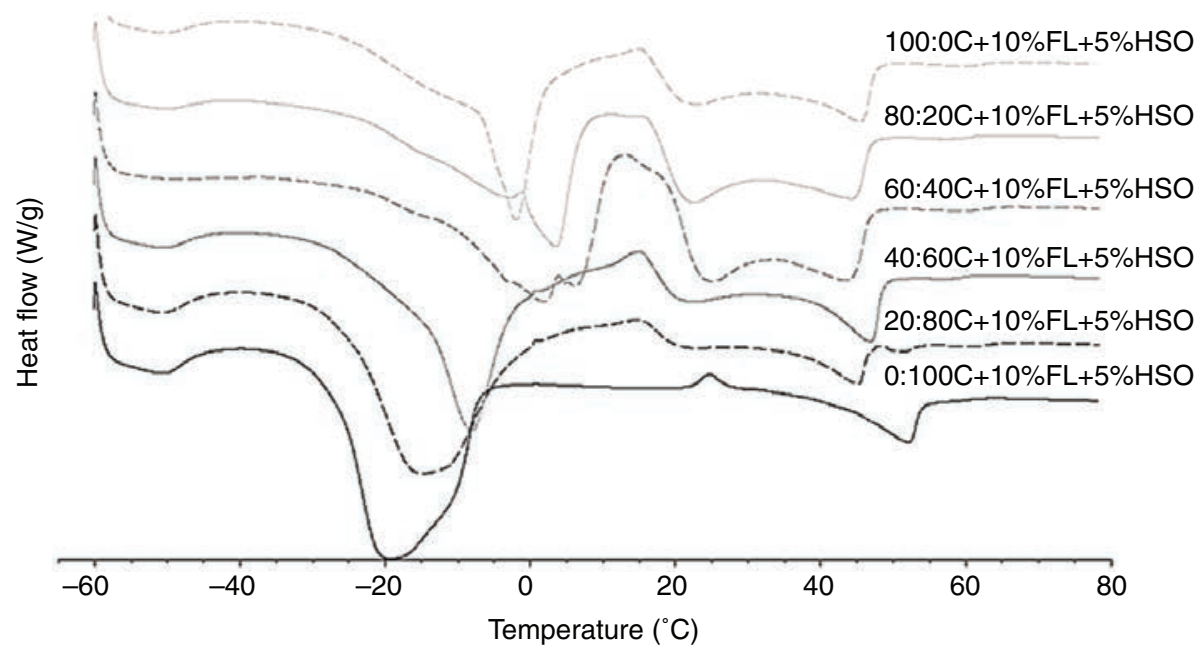

FIGURE 10. Melting behavior for the blends added with $10 \%$ free phytosterols and 5\% hydrogenated soybean oil $(100: 0 \mathrm{C}+10 \% \mathrm{FL}$ $+5 \% \mathrm{HSO}, 80: 20 \mathrm{C}+10 \% \mathrm{FL}+5 \% \mathrm{HSO}, 60: 40 \mathrm{C}+10 \% \mathrm{FL}+5 \% \mathrm{HSO}, 40: 60 \mathrm{C}+10 \% \mathrm{FL}+5 \% \mathrm{HSO}, 20: 80 \mathrm{C}+10 \% \mathrm{FL}+5 \% \mathrm{HSO}$, $0: 100 \mathrm{C}+10 \% \mathrm{FL}+5 \% \mathrm{HSO}$.
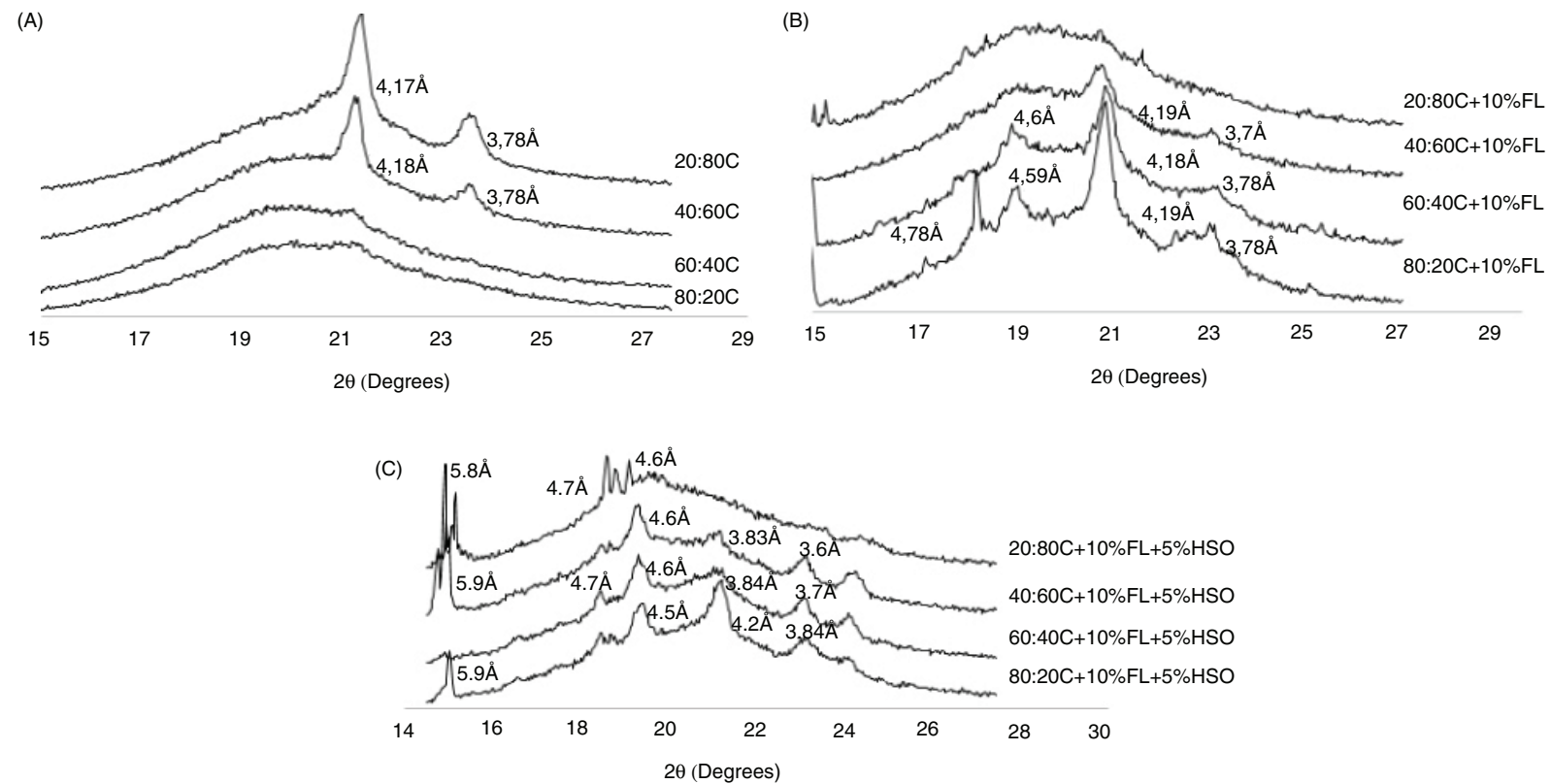

*The peaks that was not recognized as a polymorphic form is probably a free phytosterol peak.

Figure 11. Difratograms of blends; (A) Control blends; (B) Control blends added with $10 \% \mathrm{FP}$; (C) Control blends added with $10 \% \mathrm{FP}$ and $5 \% \mathrm{HSO}$

triacylglycerols from PO, since the most unsaturated triacylglycerols from $\mathrm{CO}$ are in liquid phase. The addition of FP to the reference blends (Figure 11, b) resulted on the formation of a $\beta$ crystal polymorph, as observed from the rising of short spacing of about $4.6 \AA$, simultaneously to the presence of $\beta$ '-form. In addition, the FP kept the crystallinity of the blends up to $80 \%$ of CO. It was also observed for these blends a X-ray diffraction peak at $2 \theta$ of about $15.02^{\circ}$ representing the crystal arrangement of the FP molecules. Vaikousi et al., 2007 reported X-ray diffraction lines related to FP at $2 \theta$ of $4.6,6.9,9.35,11.7,14.85,16.5,18.4$ and $21.9^{\circ}$. 
TABLE 5. Caracterization of polymorphic form in the samples through AOCS official metodology (2009)

\begin{tabular}{|c|c|c|}
\hline Blends & Short spacings (£) & Polymorphic form \\
\hline 100:0C & $4.18-3.78$ & $\beta^{\prime}$ \\
\hline $80: 20 \mathrm{C}$ & $4.17-3.78$ & $\beta$, \\
\hline $60: 40 \mathrm{C}$ & $4.18-3.78$ & $\beta$, \\
\hline $40: 60 \mathrm{C}$ & - & - \\
\hline $20: 80 \mathrm{C}$ & - & - \\
\hline $0: 100 \mathrm{C}$ & - & - \\
\hline 100:0FP & $4.18-4.58-3.77$ & $\beta+\beta^{\prime}$ \\
\hline $80: 20 \mathrm{FP}$ & $4.19-4.59-3.78$ & $\beta+\beta^{\prime}$ \\
\hline $60: 40 \mathrm{FP}$ & $4.60-4.18-3.78$ & $\beta+\beta^{\prime}$ \\
\hline 40:60FP & $4.60-4.19-3.78$ & $\beta+\beta^{\prime}$ \\
\hline $20: 80 \mathrm{FP}$ & - & - \\
\hline $0: 100 \mathrm{FP}$ & - & - \\
\hline 100:0 FP - HSO & $4.59-4.19-3.84$ & $\beta+\beta^{\prime}$ \\
\hline 80:20 FP - HSO & $4.59-4.19-3.84$ & $\beta+\beta^{\prime}$ \\
\hline 60:40 FP - HSO & $4.59-3.84$ & $\beta+\beta^{\prime}$ \\
\hline 40:60 FP - HSO & $4.58-3.83$ & $\beta+\beta^{\prime}$ \\
\hline 20:80 FP - HSO & 4.60 & $\beta$ \\
\hline 0:100 FP - HSO & 4.60 & $\beta$ \\
\hline
\end{tabular}

a -: Sample liquids in the temperature of analysis.

The systems containing FP and HSO (Figure 11, c), presented $\beta$-form and $\beta$ '-form, and the peak related to FP $\left(2 \theta\right.$ about $\left.15^{\circ}\right)$ for CO contents up to $60 \%$. The diffractograms of systems 20:80-FP-HSO and $0: 100-F P-H S O$ showed only crystal polymorph and the peak related to FP, without $\beta^{\prime}$ form. In these last two systems there are great amount of tryacylglycerols in liquid phase, once high fractions of $\mathrm{CO}$ are present, solubilizing less stable polymorphs and facilitating the transition $\beta$ '-form to $\beta$-form due to high molecular mobility for the crystal clusters. FP induce crystallization at $\beta$-form, simultaneously to a previous original $\beta^{\prime}$-form, possibly working as impurities in which solid surface the triacylglycerols can bind, leading to a heterogeneous crystallization process. This mechanism probably changes the triacylglycerol arrangement in crystal structure, modifying the polymorphism of a fraction of the total triacylglycerols in the blends. In turn, HSO has high content of symmetric triacylglycerols, a type of molecule that promotes $\beta$ polymorph, leading to formation of this kind of arrangement in fatty systems.

\section{CONCLUSIONS}

The addition of 10\% FP into blends of PO:CO, and its association with low fractions of HSO shows promising results for the modification of the physical properties and crystallization behavior of these systems. The results of fatty acid composition show that it was possible to reduce the saturated fatty acid contents in the control blends (reduction of 39.5\%) and in the blends containing HSO (reduction of $37.5 \%$ ), with respective increase in monounsaturated and polyunsaturated fatty acids. FP allows obtaining blends with lower amounts of PO and similar, or more stable in relation to temperature, consistency, solid fat content and thermal behavior. The addition of this compound improved the crystalline network of the systems, decreased the average crystal sizes and increased the crystallinity of the systems with high contents of CO. In addition, FP promoted changes in the polymorphism of the fatty systems, causing the rising $\beta$-form simultaneously to $\beta$ '-form. HSO associated to FP, shifted the crystallization of the fatty mixtures to higher temperatures, increasing their SFC and the crystal networks, and decreasing crystal sizes. Additionally, HSO promote polymorphic transition $\beta$ '-form to $\beta$-form for systems with higher contents of $\mathrm{CO}$.

This study showed the effectiveness of the structuring of lipid blends for applications in foods. According to the solid fat content results, easily related to industrial application, the blends 60:40 and 40:60, 60:40-FP and 40:60-FP and 60:40-FP-HSO and 40:60-FP-HSO can be used in products which require good spreadability, such as margarine and spreads; and the blends 60:40-FP, 80:20-FP, 100:0FP, 40:60-FP-HSO, 60:40-FP-HSO, 80:20-FP-HSO and 100:0-FP-HSO can be used in products to avoid oil exudation, as spreads at intermediate temperatures $\left(25^{\circ} \mathrm{C}\right)$. Subsequent steps to this study involve the incorporation of the developed blends in food formulations, verifying their interaction with other ingredients and sensorial characteristics.

\section{ACKNOWLEDGMENTS}

To the Fundação de Amparo à Pesquisa do Estado de São Paulo - FAPESP (Proc. 2009/53006-0 and Proc. 2013/19424-5).

\section{REFERENCES}

AOCS. American Oil Chemists' Society, 2009. Official methods and recommended practices of the American Oil Chemists' Society, 6th Editio. ed. Champaign. http:// dx.doi.org/10.1002/0471740039.vec0152

Auriou N. 2004. Stabilized dispersion of phytosterol in oil. US 20040156887.

Bot A, Agterof WGM. 2006. Structuring of edible oils by mixtures of $\gamma$-oryzanol with $\beta$-sitosterol or related phytosterols. J. Am. Oil Chem. Soc. 83, 513-521.

Campos R. 2005. Fat Crystal Networks, in: Fat Crystal Networks. Marcell Dekker Inc., New York, pp. 267-349.

Cerdeira M, Martini S, Candal RJ, Herrera, ML, 2006. Polymorphism and growth behavior of low-trans fat blends formulated with and without emulsifiers. $J$. Am. Oil Chem. Soc. 83, 489-496. https://doi.org/10.1007/ s11746-006-1231-x

Co ED, Marangoni AG. 2012. Organogels: An alternative edible oil-structuring method. J. Am. Oil Chem. Soc. 89, 749-780. http://doi.org/10.1007/s11746-012-2049-3 
Connor SL, Gustafson JR, Flavell DP, Artaud-wild SM, Hatcher CJCLF, Connor WE. 1986. The cholesterol/ saturated-fat index: An indication of the hypercholesterolaemic and atherogenic potential of food. Lancet 8492, $1229-1232$.

Dhaka V, Gulia N, Ahlawat KS, Khatkar BS. 2011. Trans fatssources, health risks and alternative approach - A review. J. Food Sci. Technol. 48, 534-541. https://doi.org/10.1007/ s13197-010-0225-8

Dubois V, Breton S, Linder M, Fanni J, Parmentier M. 2007. Fatty acid profiles of 80 vegetable oils with regard to their nutritional potential. Eur. J. Lipid Sci. Technol. 109, 710 732. http://doi.org/10.1002/ejlt.200700040

Gebauer SK, Tracy RP, Baer DJ. 2014. Impact of stearic acid and oleic acid on hemostatic factors in the context of controlled diets consumed by healthy men. Eur. J. Clin. Nutr. 2600, 1-3. http://doi.org/10.1038/ejen.2014.62

Gunstone FD, Harwood JL, Dijkstra AT. 2007. The Lipid Handbook, in: The Lipid Handbook. CRC Press, Boca Raton, pp. 37-141.

Haighton AJ. 1959. The measurement of the hardness of margarine and fats with cone penetrometers. J. Am. Oil Chem. Soc. 36, 345-348. http://doi.org/10.1007/BF02 640051

Hartman L, Lago RCA. 1973. No Title. Lab. Pract. 22, 475-476.

Herrera ML, Marquez Rocha FJ. 1996. Effects of sucrose ester on the kinetics of polymorphic transition in hydrogenated sunflower oil. J. Am. Oil Chem. Soc. 73, 321-326. http:// doi.org/10.1007/BF02523425

Kim BH, Lumor SE, Akoh CC. 2008. trans -Free Margarines Prepared with Canola Oil / Palm Stearin / Palm Kernel Oil-Based Structured Lipids. J. Agric. Food Chem. 56, 8195-8205.

Lida HMDN, Ali RM. 1998. Physico-chemical characteristics of palm-based oil blends for the production of reduced fat spreads. J. Am. Oil Chem. Soc. 75, 1625-1631. http://doi. org/10.1007/s11746-998-0103-y

Metzroth DJ. 2015. Shortenings: Science and Technology, in: Bailey's Industrial Oil and Fat Products.

Moreau RA, Whitaker BD, Hicks KB. 2002. Phytosterols, phytostanols, and their conjugates in foods: Structural diversity, quantitative analysis, and health-promoting uses. Prog. Lipid Res. 41, 457-500. http://doi.org/10.1016/ S0163-7827(02)00006-1

Noakes M, Clifton PM, Doornbos AME, Trautwein EA. 2005. Plant sterol ester-enriched milk and yoghurt effectively reduce serum cholesterol in modestly hypercholesterolemic subjects. Eur. J. Nutr. 44, 214-222. http://doi.org/10.1007/ s00394-004-0513-z

O'Brien RD. 2004. Fats and oils: formulating and processing for applications, New York.

Oliveira GM, Badan Ribeiro AP, dos Santos AO, Cardoso LP, Kieckbusch TG. 2015. Hard fats as additives in palm oil and its relationships to crystallization process and polymorphism. LWT - Food Sci. Technol. 63, 1163-1170. http:// doi.org/10.1016/j.lwt.2015.04.036

Pernetti M, van Malssen KF, Flöter E, Bot A. 2007. Structuring of edible oils by alternatives to crystalline fat. Curr. Opin. Colloid Interface Sci. 12, 221-231. http://doi.org/10.1016/j. cocis.2007.07.002
Przybylski R, Mag T, Eskin NM, McDonald BE. 2005. Canola Oil. Bailey's Ind. Oil Fat Prod. 61-121. http://doi. org/10.1002/047167849X.bio004

Raczyk M, Kmiecik D, Przybylski R, Rudzińska M. 2017. Effect of Fatty Acid Unsaturation on Phytosteryl Ester Degradation. J. Am. Oil Chem. Soc. 94, 701-711. http:// doi.org/10.1007/s11746-017-2979-x

Ribeiro APB, Basso RC, dos Santos AO, Andrade GC, Cardoso LP, Kieckbusch TG. 2013. Hardfats as crystallization modifiers of cocoa butter. Eur. J. Lipid Sci. Technol. 115, $1462-1473$

Ribeiro APB, Masuchi MH, Miyasaki EK, Domingues MAF, Stroppa VLZ, de Oliveira GM, Kieckbusch TG. 2015. Crystallization modifiers in lipid systems. J. Food Sci. Technol. 52, 3925-3946. http://doi.org/10.1007/s13197-014-1587-0

Rogers MA, Strober T, Bot A Toro-Vazquez JF, Stortz T, Marangoni AG. 2014. Edible oleogels in molecular gastronomy. Int. J. Gastron. Food Sci. 2, 22-31. http://doi. org/10.1016/j.ijgfs.2014.05.001

Rousset P. 2002. Physical Properties of Lipids, in: Physical Properties of Lipids. Marcell Dekker Inc., New York, pp. 1-36.

Rozner S, Garti N. 2006. The activity and absorption relationship of cholesterol and phytosterols. Colloids Surfaces A Physicochem. Eng. Asp. 282-283, 435-456. http://doi. org/10.1016/j.colsurfa.2005.12.032

Salo P, Wester I. 2005. Low-fat formulations of plant stanols and sterols. Am. J. Cardiol. 96, 10-13. http://doi.org/10.1016/j. amjcard.2005.03.021

Senate Commission on Food Safety, 2014. Phytosterol oxidation products in foods: Analysis, occurrence, exposure and biological effects. Dtsch. Forschungsgemeinschaft 34. http:// doi.org/10.13140/2.1.1369.4248

Smith KW, Bhaggan K, Talbot G, Van Malssen K.F. 2011. Crystallization of fats: Influence of minor components and additives. J. Am. Oil Chem. Soc. 88, 1085-1101. http:// doi.org/10.1007/s11746-011-1819-7

Timms RE. 1984. Phase behaviour of fats and their mixtures. Prog. Lipid Res. 23, 1-38. https://doi. org/10.1016/0163-7827(84)90004-3

Ulbricht TLV, Southgate DT. 1991. Coronary heart disease: seven dietary factors. Lancet 338, 985-992. http://doi. org/10.1016/0140-6736(91)91846-M

Vaikousi H, Lazaridou A, Biliaderis CG, Zawistowski J. 2007. Phase transitions, solubility, and crystallization kinetics of phytosterols and phytosterol-oil blends. J. Agric. Food Chem. 55, 1790-1798. http://doi.org/10.1021/if0624289

Wassell P, Bonwick G, Smith CJ, Almiroin-Roig E, Young NWG. 2010. Towards a multidisciplinary approach to structuring in reduced saturated fat-based systems - a review. Int. J. Food Sci. Technol. 45, 642-655.

Wassell P, Young NWG. 2007. Food applications of trans fatty acid substitutes. Int. J. Food Sci. Technol. 42, 503-517. http://doi.org/10.1111/j.1365-2621.2007.01571.x

Yap P, Man J, Man L. 1989. Polymorphism of palm oil and palm oil products. J. Am. Oil Chem. Soc. 66, 693-697. https:// doi.org/10.1007/BF02669954

Zevenbergen H, De Bree A, Zeelenberg M, Laitinen K, Van Duijn G, Flöter E. 2009. Foods with a high fat quality are essential for healthy diets. Ann. Nutr. Metab. 54, 15-24. http://doi.org/10.1159/000220823 